\title{
Computer Simulation of Surface Cracks Behavior in Anhydrous Chemical Conversion Coatings on Magnesium Alloy
}

\author{
Li Lijie1, $\quad$ Fang Yongchao $^{2}, \quad$ Cai Zhaobing ${ }^{2}, \quad$ Cui Xiufang ${ }^{2}, \quad$ Liu Erbao $^{2}, \quad$ Jin Guo ${ }^{2}$ \\ ${ }^{1}$ College of Computer Science and Technology, Harbin Engineering University, Harbin 150001, China; ${ }^{2}$ Institute of Surface/Interface Science \\ and Technology, Key Laboratory of Superlight Material and Surface Technology of Ministry of Education, College of Material Science and \\ Chemical Engineering, Harbin Engineering University, Harbin 150001, China
}

\begin{abstract}
In the conversion coatings, some uniformly distributed micro surface cracks always occur but the surface cracks behavior is rarely studied due to the frequent initiation in the real test conditions. In this work, computer simulation of micro surface cracks behavior and internal stresses generated in the anhydrous chemical conversion coating was carried out using the finite element method with the help of ABAQUS software. The Mises stress distribution, $S_{11}$ stress variation, and the stress-time curves were obtained. The results show that the internal stresses generated in the conversion coating increase obviously with increasing time, and the stresses at the center and boundary of coating pieces are bigger than the ones in other areas while the $S_{11}$ stresses around the center are bigger than the ones near the boundary. The cracks at the interface of coating pieces develop gradually and are as V-type cracks finally. The width of crack mouth opened is different since the contraction degree of each coating piece is different.
\end{abstract}

Key words: surface cracks; conversion coatings; magnesium alloy; computer simulation

Corrosion resistance of magnesium alloy can be effectively improved by the anhydrous chemical rare-earth conversion coatings ${ }^{[1-3]}$. However, experimental results show that some uniformly distributed micro surface cracks always occur in the conversion coatings ${ }^{[4-8]}$. These cracks may cause the coatings surface discontinuity and decrease the accuracy of the electrochemistry test result $6 \sim 9^{[9-12]}$. Furthermore, they may weaken the adhesion ability of coating-substrate interface and affect the capability of coatings ${ }^{[13,14]}$. It is therefore necessary to study the behavior of coating surface cracks initiation and development and thereby ameliorate this situation.

It is difficult to investigate the initiation and development of the coating micro surface cracks during the coating formation in real test conditions. However, computer simulation may give the possibility to learn it and to understand the relationships among various parameters and makes it possible to select the proper solution ${ }^{[12-15]}$. In this paper, there are several factors which have effect on surface morphology and the change of internal stresses with the conversion coating during the cracking, including water evaporation rate, chemical composition and the thickness of conversion coating. The simulation results reflect the micro conclusion which cannot be given in the experiment and provide a theory basis for cracking and controlling of flaws of conversion coating. Thus, the development of computer simulations has significant meaning on the application and the optimization of conversion coatings.

In this paper, computer simulation of micro surface cracks and internal stresses generated in the conversion coating was carried out in ABAQUS environment, which has a stronger ability of contact analysis, using the FEM

$\overline{\text { Received date: June } 25,2017}$

Foundation item: National Key Basic Research Program of China (“973” Program) (61328303); National Natural Science Foundation of China (51575118, 51375106); Fundamental Research Funds for the Central Universities (HEUCFP201608, HEUCFM160601)

Corresponding author: Liu Erbao, Ph. D., Lecturer, College of Material Science and Chemical Engineering, Harbin Engineering University, Harbin 150001, P. R. China, Tel: 0086-451-82589660,E-mail: liutong_05@163.com 
(Finite Element Method) method ${ }^{[16-18]}$.

\section{Experiment}

\subsection{Preparation of samples}

The AZ91D magnesium alloy of size $15 \mathrm{~mm} \times 10 \mathrm{~mm} \times 10$ $\mathrm{mm}$ was used as substrate material in the present study. Its chemical composition (wt\%) is: Al 8.5 9.5, $\mathrm{Zn} \mathrm{0.45} \mathrm{0.9,}$ Mn 0.17 0.4, $\mathrm{Si} \leq 0.05, \mathrm{Cu} \leq 0.025, \mathrm{Ni} \leq 0.001$, and $\mathrm{Fe} \leq$ 0.004 and $\mathrm{Mg}$ in balance. The conversion coating was obtained on the matrix of die-cast AZ91D. The substrate was polished using water proof abrasive paper from $360 \#$ grits to $2500 \#$ grits, then fine polished using diamond paste of $3.5 \mu \mathrm{m}$, rinsed with acetone and deionized water and dried with hot air. The conversion coating was formed on AZ91D by immersion of samples for $20 \mathrm{~min}$ in the solutions.

\subsection{Model description}

SEM was used to reveal the morphology of the conversion coating. One of the experimental results is shown in Fig. 1, where, it can be seen that different polygon shaped micro crack pieces are uniformly distributed on the whole in the conversion coating in Fig.1a. Most of the crack pieces are about $10 \mu \mathrm{m}$ in diameter and $2 \sim 3 \mu \mathrm{m}$ in thickness. The average thickness of the conversion coating layer is $2 \sim 3 \mu \mathrm{m}$ and the maximum value reaches to $5 \mu \mathrm{m}$ in Fig. $1 \mathrm{~b}$. It can be seen that the maximum ratio of diameter of the crack pieces and the thickness of the conversion coating layer is $5: 1$.

According to the experimental results, the model of coating layer and substrate is set and shown in Fig. 2. When creating a model, select an irregular layer composed of a hexagonal mosaic as conversion coating layer was selected, in order to promote the operation of simulation. The hexagon conversion coating layers were patched and crack would initiate at the interface of coating layers. The boundaries between hexagons were crack sources, and connected on hexagonal planes. The border length of the hexagon layers is 2, and the thickness of the layers was 0.4 , the number of the length and the thickness were set according to the proportion of actual conversion coating size, and the basic unit can be considered meter, based on the subsequent setting of physical and chemical parameters. Since the actual thickness of the AZ91D magnesium alloy substrate is much thicker than that of the conversion coating, cracking conversion coating had no effect on the magnesium alloy surface. Hence, the model geometry value of $\mathrm{Mg}$ alloy substrate can be set discretionarily.
The properties of the conversion coating and the substrate based on the actual situation were set in the model. AZ91D magnesium alloy was the substrate, and conversion coating composition which is much more complex than substrate was given priority to oxide and hydroxide. Values were derived from nature of the magnesium oxide, and the manual was found to get the performance parameters of the conversion coating and the magnesium alloy substrate. Hexagon layers, which contacted each other, cracked along the contacting surface; moreover partial spalling is occurred in some conversion coating and substrate. Therefore contacting properties of each hexagon layers and coating-substrate interface need to be determined under further analysis and calculation. The necessary parameters (properties of coating and substrates materials, bond stiffness of hexagon layers border and coating-substrate interface) for finite element analysis are shown in Table 1 and Table 2, respectively.

\subsection{Simulation analysis}

It was found that the surface cracks in the coating initiated and developed when the moisture of coating vaporized in the

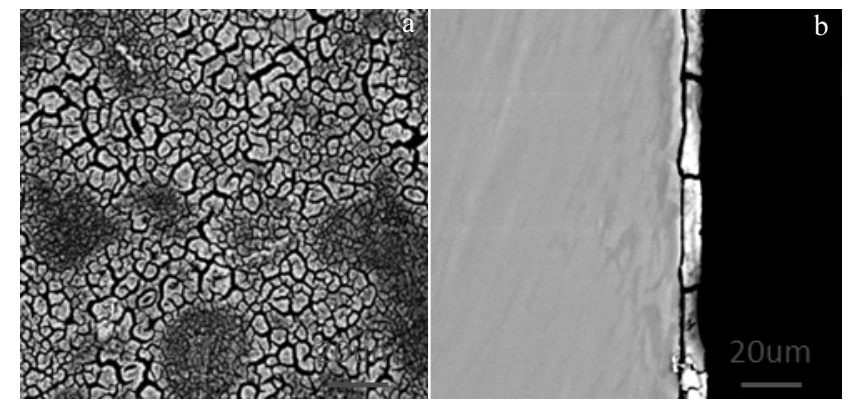

Fig. 1 Crack pieces in conversion coating: (a) coating surface and (b) coating section

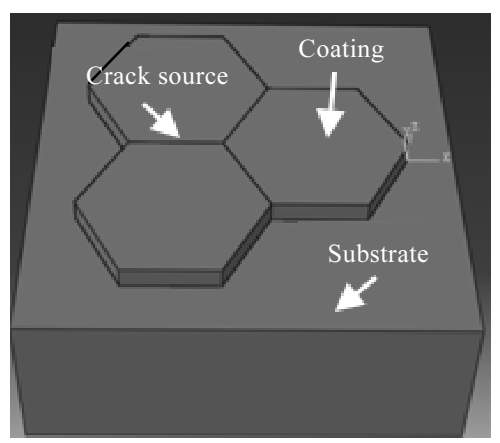

Fig. 2 Model of coating layer and substrate

Table 1 Property parameters of conversion coating layer and magnesium alloy substrate

\begin{tabular}{ccccccc}
\hline Parameter & $E / \mathrm{GPa}$ & $v$ & $\rho / \mathrm{kg} \cdot \mathrm{m}^{-3}$ & $C / \mathrm{J} \cdot\left(\mathrm{kg} \cdot{ }^{\circ} \mathrm{C}\right)^{-1}$ & $k / \mathrm{W} \cdot\left(\mathrm{m} \cdot{ }^{\circ} \mathrm{C}\right)^{-1}$ & $\alpha / \times 10^{-6} \mathrm{~m} \cdot\left(\mathrm{m} \cdot{ }^{\circ} \mathrm{C}\right)^{-1}$ \\
\hline Conversion coating & 5.5 & 0.3 & 3580 & 877.8 & 30 & 8.0 \\
Magnesium substrate & 450 & 0.3 & 18200 & 1050 & 72 & 25 \\
\hline
\end{tabular}

Note: $E$-Young's modulus; $v$-Poisson's ratio; $\rho$-density; $C$-specific heat; $k$-heat conductance; $\alpha$-expansion coefficient 
Table 2 Bond stiffness of hexagon layers border and coating substrate interface

\begin{tabular}{cccc}
\hline Stiffness & Knn & Kss & $K \mathrm{tt}$ \\
\hline Hexagon layers border & 100 & 100 & 100 \\
Coating-substrate interface & 200 & 200 & 200 \\
\hline
\end{tabular}

Note: $K$-bond stiffness, $K$ nn-normal stiffness, $K$ ss-hexagon layers in the plane, Ktt-coating-substrate interface stiffness in the plane

air and it induced the change of internal stresses. The stresses induced by the heat transfer both between the coating with substrate, and the coating with air was therefore taken into account in the FE model. In fact, the moisture and composition of coating may be different in different areas of the same coating, since the precipitates may be different during the conversion coating-forming process. Besides, moisture of the top surface contacted with the air vaporized faster than the one of inner area of coating. The upper coating surface therefore showed more contractive and micro cracks thus occurred. Consider all above situations, three layers of the conversion coating A, B, and $\mathrm{C}$ with different temperature were set in the model (Fig. $3 \mathrm{a}$ ), where the temperature was 27,23 , and $25^{\circ} \mathrm{C}$, respectively; the substrate was $27{ }^{\circ} \mathrm{C}$, and the circumambience air was $23^{\circ} \mathrm{C}$. The heat convection was set as natural convection and the convection coefficient was 10 . Fig. 3 shows the condition setting and the finite element model mesh used to simulate the internal stresses.

Computer simulation of internal stresses generated in the conversion coating and magnesium alloy substrates was carried out in ABAQUS environment, using the FEM method. In order to get more veracious result, the calculation time was set as $36000 \mathrm{~s}$, and 29 steps were performed.

\section{Results and Discussion}

The Mises stress distribution obtained from computer simulation is shown in Fig.4. Fig. 4a gives the stress map at the beginning of simulation, and Fig. $4 \mathrm{~b}$ shows the result at the first step, Fig.4c is the stress distribution map at step 16, and Fig. $4 d$ gives the simulation result at the last step. Fig. $4 \mathrm{e}$ is the staff gauge of stress variation. From Fig. 4a, it can be seen that all stresses are in the same level since no heat transformation occurs at the beginning of simulation. Some stress variation at the interface of coating layers can be seen in Fig. $4 \mathrm{~b}$ and it also can be seen that the stresses in layer B are bigger than the ones in $\mathrm{A}$ and $\mathrm{C}$. There is no crack split in the coating pieces. In Fig. 4c, namely, at step 16, the stress variation at the interface of coating layers increases obviously and a slight crack split at the interface of coating layers B and C can be seen. At the last step (see Fig. 4d), it is evident that stresses uniformly distributed in all the three layers increase more obviously. The three cracks have developed obviously and have been being as V-type cracks at the interface of coating layers. Since the contraction degree of each coating layer is different, the width of crack mouth is different accordingly.

From the stress distribution map at different steps, the internal stress variation and the crack initiation and development situation in coating can be clearly understood. The Mises stress distribution and the stress-time curves from the center to the boundary of coating layer $\mathrm{C}$ are shown in Fig. 5a and 5b, respectively. That is in agreement with the result in Fig. 5b, where, stresses of point 1 (at the center) and 6 (at the boundary) are bigger than other ones. The stress of point 3 is smaller than others. The curves of all points change in the same trend and conform to the law of correlation. It can be seen that stresses are concentrated at the center and at the boundary. The $S_{11}$ stress (along the direction of $x$-axis) variation and the stress-time curves from the center to the boundary of coating layer $\mathrm{C}$ along the $x$-axis are shown in Fig. $5 \mathrm{c}$ and $5 \mathrm{~d}$, respectively. From Fig. $5 \mathrm{c}$ it can be seen that the stress around the center is bigger than that near the boundary. Fig. $5 \mathrm{~d}$ shows that stresses of point 1 4 increase quickly at first and then the values become zero at about $6000 \mathrm{~s}$; after that, they move toward the negative direction along the $x$-axis and the absolute values increase continually. Whereas, the absolute stress values of point 5 and 6 are different from those of point $1 \sim 4$ obviously. The stress of point 1 is bigger than others, and the point 4 is reverses. It is in agreement with the result of Fig. 5c, namely, the stresses around the center are bigger than the ones near the boundary. It also suggests that stresses of coating $\mathrm{C}$ are restricted by not only the surface

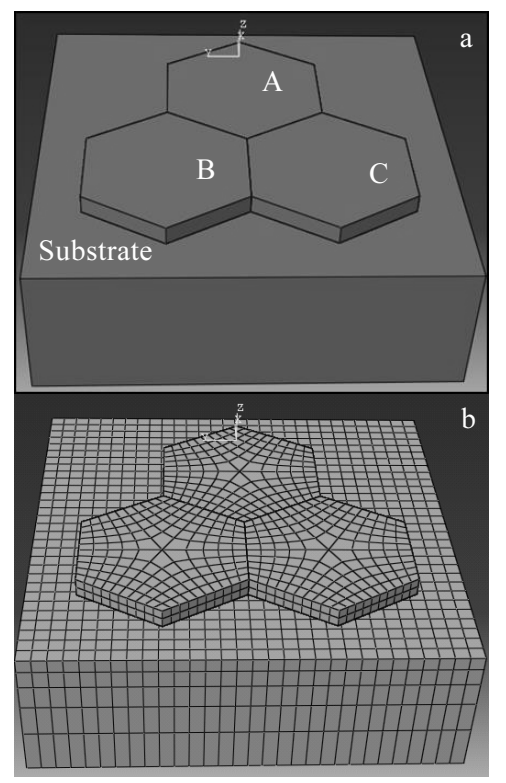

Fig. 3 FE model of crack pieces in conversion coating: (a) condition setting and (b) FE-mesh 


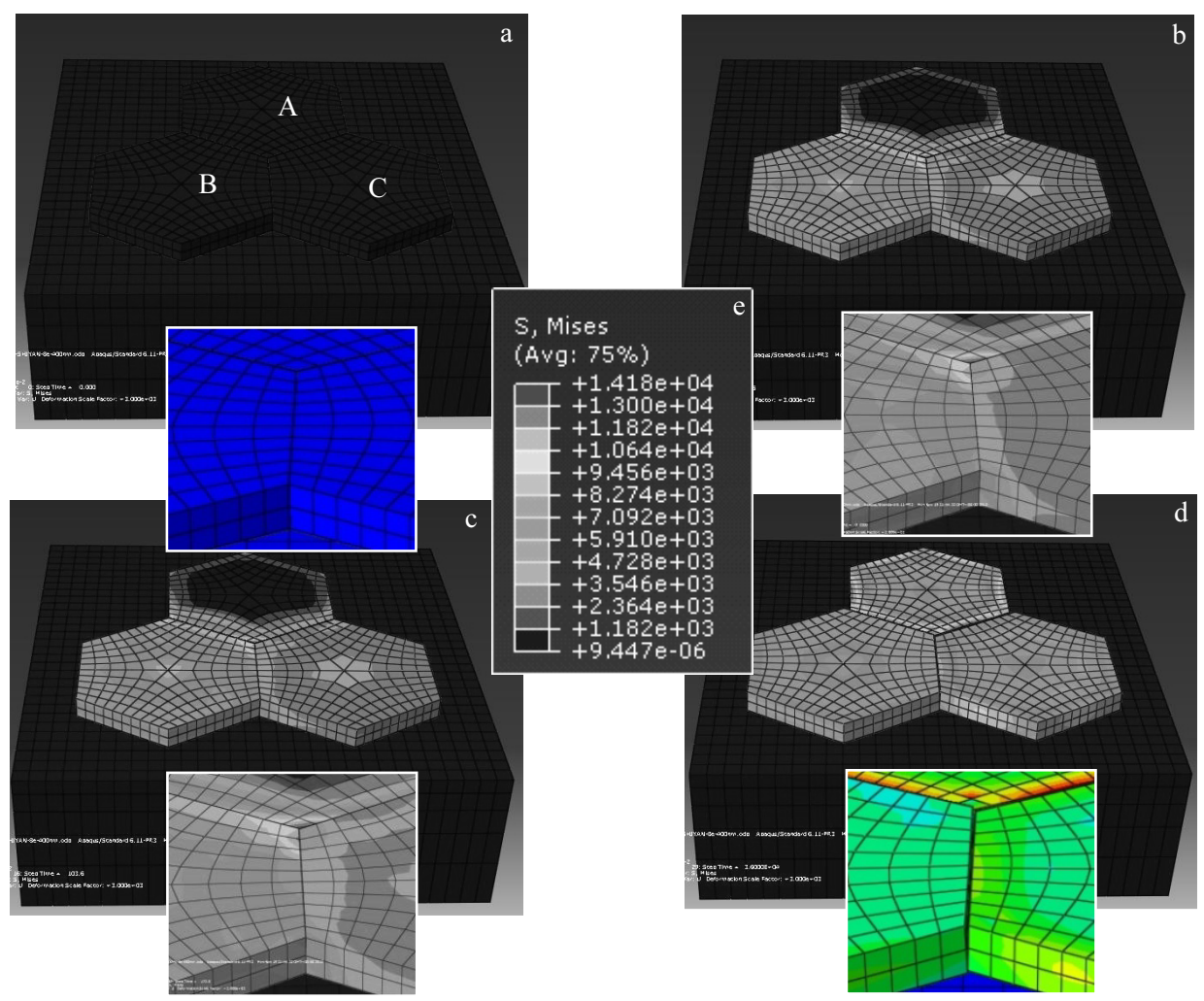

Fig.4 Mises stress distribution in conversion coating: (a) beginning simulation stress map, (b) first step result, (c) stress distribution map at step 16, (d) last step result, and (e) staff gauge of stress variation
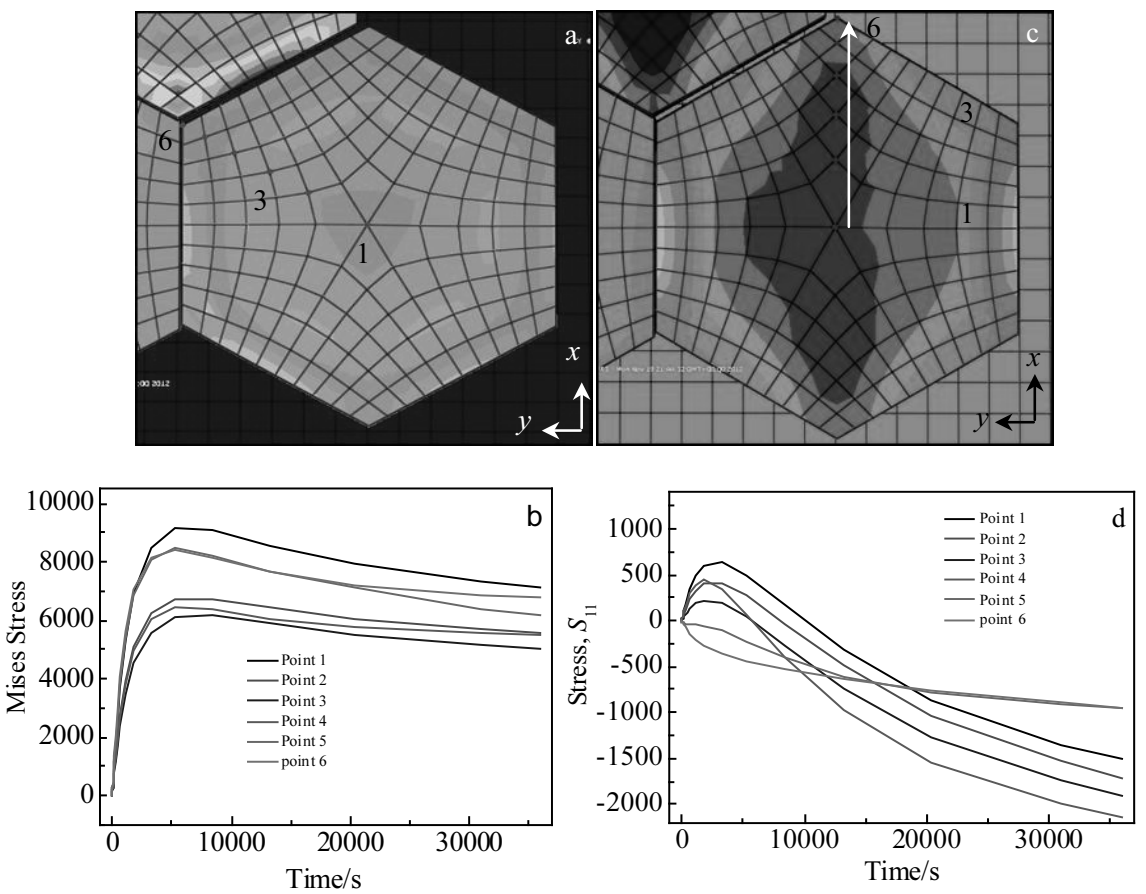

Fig. 5 Stress distribution (a, c) and stress-time curves in coating C (b, d): (a, b) Mises stress distribution; (c, d) $S_{11}$ stress variation 
temperature which gives a negative stress along the $x$-axis when temperature decreases and induces the coating contraction, but also by the adjoining coating A, which gives a positive stress along the $x$-axis. Therefore stresses of point 1 4 increase quickly before crack initiation, and then move toward the negative direction along the $x$-axis when cracks develop and the restricted effect of the adjoining coating A decreases ${ }^{[19]}$.

\section{Conclusions}

1) Computer simulation of micro surface cracks and internal stresses generated in the conversion coating is carried out by FEM. The Mises stress distribution, $S_{11}$ stress variation, and the stress-time curves are obtained.

2) From the results at different steps, the internal stresses variation and the crack behavior in coating can be clearly understood. It is evident that the internal stresses generated in the conversion coating increase obviously with increasing time, and the stresses at the center and boundary of coating pieces are bigger than the ones in other areas. The cracks at the interface of coating pieces develop gradually and are as V-type cracks finally. The width of crack mouth opened is different since the contraction degree of each coating piece is different. The $S_{11}$ stresses around the center are bigger than the ones near the boundary.

\section{References}

1 Cui Xiufang, Li Qingfen, Li Ying et al. Applied Surface Science[J], 2008, 255: 2098

2 Wang Guixiang, Cao Nana, Zhang Xiaohong. Rare Metal Materials and Engineering[J], 2017, 46(6): 1480

3 Jin Guo, Yang Yuyun, Cui Xiufang et al. Material Letter[J], 2011, 65: 1145
4 Huang Zhiquan, Huang Qingxue, Wei Jianchun. Rare Metal Materials and Engineering[J], 2016, 45(6): 1461 (in Chinese)

5 Nordlien J, Walmsley J, Østerberg H et al. Surface and Coatings Technology [J], 2002, 153: 72

6 Zhao Ming, Wu Shusen, Luo Jirong et al. Surface and Coatings Technology[J], 2006, 200: 5407

$7 \mathrm{Su}$ Chunjian, Li Tiantian. Rare Metal Materials and Engineering[J], 2015, 44(3): 649 (in Chinese)

8 Liu Yanwen, Feng Z, John Walton et al. Surface and Interface Analysis[J], 2013, 45: 1446

9 Zhong Xin, Wu Xiaosong, Jia Yali et al. Applied Surface Science[J], 2013, 280: 489

10 Ramezanzadeh B, Attar M, Farzam M. Surface and Coatings Technology[J], 2010, 205: 874

11 Zhao Ming, Li Jianguo, He Guangping et al. Applied Surface Science [J], 2013, 282: 499

12 Lunder O, Walmsley J, Mack P et al. Corrosion Science[J], 2005, 47: 1604

13 Wang Cheng, Zhu Shenglong, Jiang Feng et al. Corrosion Science[J], 2009, 51: 2916

14 Lin C S, Lee C Y, Li W C et al. Journal of the Electrochemical Society[J], 2006, 153: B90

15 Jansson N, Leterrier Y, Medico L et al. Thin Solid Films[J], 2006, 515: 2097

16 Dong Hairong, Ma Ying, Guo Huixia. Rare Metal Materials and Engineering [J], 2017, 46(6): 1656 (in Chinese)

17 Zhang Jin, Chan Yengfong, Yu Qingsong. Progress in Organic Coatings[J], 2008, 61: 28

18 Husain E, Narayanan T, Taha-Tijerina J et al. ACS Applied Materials \& Interfaces[J], 2013(5): 4129

19 Shi Pengpeng, Sun Sha, Li Xing. Engineering Fracture Mechanics[J], 2013, 105: 238

\title{
镁合金无水化学转化膜表面裂纹行为的计算机模拟
}

\author{
李丽洁 ${ }^{1}$, 房永超 ${ }^{2}$, 蔡召兵 ${ }^{2}$, 崔秀芳 ${ }^{2}$, 刘二宝 ${ }^{2}$, 金 国 ${ }^{2}$ \\ (1. 哈尔滨工程大学 计算机学院, 黑龙江 哈尔滨 150001) \\ (2. 哈尔滨工程大学 材料科学与化学工程学院 超轻材料与表面技术教育部重点实验室 表界面科学与技术研究所, \\ 黑龙江 哈尔滨 150001)
}

\begin{abstract}
摘 要: 在转化膜中, 总会出现许多均匀分布的表面裂纹。但是表面裂纹行为很少被研究到, 这是由于在实际的测试条件下, 裂纹很 快就萌生完成了。在本研究中, 借助 ABAQUS 软件, 采用有限元的研究方法实现无水化学转化膜表面微裂纹行为及内应力产生的计 算机模拟, 得到 Mises 应力分布、 $S_{11}$ 应力演变和应力-时间曲线。结果表明, 转化膜在开裂过程中, 内应力随着时间增加而增大, 膜片 中心处和裂纹边缘处的应力比其他地方都大, 然而中部区域的 $S_{11}$ 应力要比靠近边界区域的 $S_{11}$ 应力大。裂纹在转化膜膜片之间慢慢产 生最终形成 $\mathrm{V}$ 型的裂纹。随着转化膜膜片收缩角度的不同, 相互间的裂纹开口宽度也不相同。
\end{abstract}

关键词: 表面裂纹; 转化膜; 镁合金; 计算机模拟

作者简介: 李丽洁, 女, 1980 年生, 博士, 讲师, 哈尔滨工程大学计算机学院, 黑龙江 哈尔滨 150001, 电话: 0451-82589660, E-mail: lilijie@hrbeu.edu.cn 